Research Article

\title{
Comprehensive Evaluation of Blast Casting Results Based on Unascertained Measurement and Intuitionistic Fuzzy Set
}

\author{
Li Ma, ${ }^{1}$ Jianguo Zhang $\mathbb{D}^{1}{ }^{1}$ Chen Xu, ${ }^{2}$ Xingping Lai $\mathbb{D}^{1},{ }^{1}$ Qiang Luo $\mathbb{D}^{1},{ }^{1}$ Chendong Liu $\mathbb{D}^{1},{ }^{1}$ \\ and $\operatorname{Kemin} \operatorname{Li}\left(\mathbb{1}^{3}\right.$ \\ ${ }^{1}$ School of Energy Engineering, Xi'an University of Science and Technology, Xi'an 710054, China \\ ${ }^{2}$ Heidaigou Open-pit Coal Mine, Shenhua Zhuge'er Energy Co., Ltd., Ordos 010300, China \\ ${ }^{3}$ School of Mines, China University of Mining \& Technology, Xuzhou 221116, China
}

Correspondence should be addressed to Jianguo Zhang; 2601814065@qq.com

Received 16 September 2020; Revised 30 October 2020; Accepted 17 January 2021; Published 29 January 2021

Academic Editor: Gilbert R. Gillich

Copyright ( $\odot 2021 \mathrm{Li} \mathrm{Ma}$ et al. This is an open access article distributed under the Creative Commons Attribution License, which permits unrestricted use, distribution, and reproduction in any medium, provided the original work is properly cited.

In order to make a scientific and accurate evaluation of blast casting results, according to the characteristics of blast castingdragline stripping system, effective casting rate, looseness coefficient, limit vibration velocity, powder factor, fragmentation distribution, muck pile shape, boulder generation, damage degree of coal seam step, and dust pollution are selected as the evaluation indicators of blast casting results, and a classification standard is established. The unascertained measure theory was adopted to determine the membership degree of influencing factor indicator, which expanded the expression method of fuzzy information of evaluation indicators. The Analytic Hierarchy Process was used to determine the subjective weight of indicators, the entropy weight method was used to determine the objective weight of indicators, and the intuitionistic fuzzy set was used to express the range of the comprehensive weights of indicators. An evaluation model of blast casting results was constructed based on unascertained measurement and intuitionistic fuzzy set. The measured and processed data of blast casting in Heidaigou OpenPit Coal Mine were calculated by the evaluation model. Besides, the sensitivity of indicator weights to the evaluation result of blast casting results was also analyzed. The results show that the blast casting results are level III (well). The effective casting rate ranks first in terms of the influence on the evaluation result, followed by damage degree of coal seam step, muck pile shape, looseness coefficient, powder factor, dust pollution, limit vibration velocity, and boulder generation/fragmentation distribution, and it was proved that the weight fluctuation of the evaluation indicator has no obvious correlation with weight.

\section{Introduction}

The blast casting-dragline stripping technology system plays an important role in surface mining. As an important technical process, blast casting can greatly reduce overburden volume stripped by dragline. Blast casting results are of great significance for improving stripping efficiency and reducing production costs. Therefore, a lot of researchers have conducted a systematic study on improving blast casting results; for example, Sharma discussed the parameters of blast casting in detail and analyzed the feasibility of applying blast casting from an economic and environmental perspective [1]; Chironis studied the factors that affect the effective casting effect and found that the inclined blast hole can improve the casting ability [2]; Mishra et al. found that blast casting can decrease the mining cost of conventional drilling and blasting methods [3]; Li et al. systematically analyzed the method of determining blasting parameters [4]; Li carried out a detailed study and determined that the blasthole density coefficient between 1.45 and 1.55 can achieve effective casting rate [5]; $\mathrm{Ma}$ et al. studied the mechanism and mechanical behavior of bench deep-hole blast casting practice and optimized the blasting parameters [6]; Ma et al. established an intelligent design model for blasting parameters, which significantly improves blast casting results [7]; Ding et al. used nonlinear theory [8], Huang et al. used ELM neural network [9], and Han et al. used BP neural network [10] in terms of predicting muck pile shape, and 
their researches provide a theoretical basis and method for the design of blast casting parameter and the prediction of blast casting results. Evaluation of blast casting results is an important part for realizing the cycle of blasting parameters design, blast results prediction and evaluation, and feedback optimization for blasting parameters.

In the evaluation of blasting results, Monjezi et al. used fuzzy set theory [11], Hu and Yang used the method of combining gray correlation and Analytic Hierarchy Process [12], Lei et al. used the Unascertained Measurement [13], and Chen et al. used the neural network method [14]. Their researches lay the foundation for the evaluation of mediumdeep-hole blasting results. In terms of application background and technical characteristics, blast casting is quite different from bench blasting, so the evaluation indicators of blast casting results are not universal. However, there are few studies on the evaluation of blast casting results. Ma et al. proposed using the efficient casting rate, looseness coefficient, shock reduction effect, and powder factor as evaluation indicators and constructed a fuzzy comprehensive evaluation model of blast casting results [15]; Zhang et al. used the randomness and ambiguity of the cloud model to construct a comprehensive evaluation cloud model of blast casting results [16]. Both models provide a reference for the blast casting result evaluation; however, the system of evaluation indicator is incomplete, so that the evaluation results have some limitations; Zhao et al. established an integrated evaluation system of gray correlation-analytic hierarchy and entropy method-analytic hierarchy, which can meet the relative comparison between the multiple blast casting results, but the lack of a unified evaluation standard makes it impossible to objectively reflect the true situation of blast casting results [17]. Therefore, it is of great significance to establish a universal blast casting result evaluation model that has universal applicability and perfect evaluation indicators and can objectively reflect the true results. In addition, the accuracy of the evaluation results is closely related to the indicators and their weights. In the current research on the evaluation of blast casting results, the following issues still exist and need to be further improved: (1) The determination of the weight of evaluation indicators is too simple; there are various subjective and objective error influences in the traditional single weighting method, which easily lead to low accuracy of the evaluation results. (2) Due to the vagueness and unknowingness of blast casting results, the ability to process the uncertainty information about the qualitative evaluation indicators is insufficient. (3) There are also few studies on the sensitivity analysis of the weight of evaluation indicators, which results in bias and lack of dynamics in the evaluation results.

Intuitionistic Fuzzy Set is an uncertain information analysis theory. It uses interval values instead of single values to represent data and expresses the essence of fuzzy information through three aspects: membership degree, nonmembership degree, and hesitation degree, so it has more flexible fuzzy information processing capabilities than traditional fuzzy theory [18-20]. Unascertained Measurement is a random, fuzzy, and uncertain mathematical method of gray information theory [21]. The use of measurement theory can objectively evaluate unascertained information in subjective cognition. The two theories are practical and alternative in dealing with uncertain problems and are widely used in systems engineering, artificial intelligence, decision-making evaluation, and other fields.

In order to improve the accuracy of the evaluation of blast casting results, this paper comprehensively selects the quantitative and qualitative evaluation indicators based on the characteristics of blast casting-dragline stripping technology system technique to make the evaluation results more reasonable and accurate. The unascertained measurement is introduced into the intuitionistic fuzzy set to determine the membership degree of the evaluation indicators which expand the expression of fuzzy information in the evaluation model. Considering the subjective and objective weighting methods, combined weights are expressed by intuitionistic fuzzy numbers. A comprehensive evaluation model of blast casting results based on unascertained measurement and intuitionistic fuzzy set is proposed. At the same time, the sensitivity of the weight range of indicators to the evaluation result is analyzed, so as to make up for the deficiency of the insufficient analysis about the impact of the evaluation indicators on blast casting results.

\section{Intuitionistic Fuzzy Set}

Suppose that there exists a domain $X$ with two mappings $m_{A}$ : $X \longrightarrow[0,1]$ and $n_{A}: X \longrightarrow[0,1]$, satisfying $m_{A}(\mathrm{x}) \in[0,1], n_{A}$ $(\mathrm{x}) \in[0,1], \mathrm{x} \in \mathrm{X}$, and $0 \leq m_{A}(x)+n_{A}(x) \leq 1$. Therefore, the intuitionistic fuzzy set $A$ is as follows [22]:

$$
A=\left\{<x, m_{A}(x), n_{A}(x)>\mid x \in X\right\}
$$

where $m_{A}(x)$ and $n_{A}(x)$ are the degrees of membership and nonmembership of element $x$ belonging to $A$, respectively.

The score value $M(A)$ and hesitation $t(A)$ of $A$ are expressed as follows:

$$
\begin{aligned}
M(A) & =m_{A}(x)-n_{A}(x), M(A) \in[-1,1], \\
t(A) & =1-m(A)-n(A) .
\end{aligned}
$$

The sum and product equations of two intuitionistic fuzzy sets $A$ and $B$ satisfy the following expressions:

$$
\begin{aligned}
A+B & =\left\{<x, m_{A}(x)+m_{B}(x)-m_{A}(x) m_{B}(x), n_{A}(x) n_{B}(x)>\mid x \in X\right\}, \\
A \cdot B & =\left\{<x, m_{A}(x) m_{B}(x), n_{A}(x)+n_{B}(x) n_{A}(x) n_{B}(x)>\mid x \in X\right\} .
\end{aligned}
$$

\section{Comprehensive Evaluation Model of Blast Casting Results}

\subsection{Evaluation System}

3.1.1. Evaluation Indicators. Blast casting results involve many uncertainties and ambiguities. Taking the characteristics of blast casting-dragline stripping technology system into consideration, the following evaluation indicators of blast casting results are comprehensively selected in terms of 
blast casting quality, economic benefits, and environmental impact.

(1) Powder factor: powder factor is an important indicator parameter in the design of deep-hole bench blasting, which affects the degree of rock looseness, fragmentation distribution, and effective casting rate. To a certain extent, powder factor not only reflects the pros and cons of blast casting results but also affects the size of various technical indicators through rock blasting and further affects the evaluation result of the blasting effect, which has both technical and economic implications. Therefore, in order to avoid the repetition of other technical indicators and the technical meaning of powder factor, this paper selects powder factor only as an economic indicator for evaluating blast casting results. Powder factor is closely related to the explosive consumption and the total amount of blasted rock, and it can be obtained by

$$
q=\frac{Q}{a \cdot b \cdot H}
$$

where $q$ is powder factor, $\mathrm{kg} / \mathrm{m}^{3} ; Q$ is explosive consumption, $\mathrm{kg}$; $a$ is hole spacing, $m$; $b$ is burden, $m$; $H$ is the bench height, $m$.

(2) Limit vibration velocity: the limit vibration velocity is a measure of the amplitude of the rock slope being vibrated by the explosion stress wave [23]. Due to the large scale and large charge of blast casting, the blasting vibration effect produced affects the stability and safety of rock slopes. In the process of blast casting, the blasting vibration tester can be used to monitor the intensity and waveform of vibration generated by blasting, so as to obtain the limit vibration velocity.

(3) Effective casting rate: the effective casting rate is the proportion of the amount of broken rock that is thrown into the mined-out area and does not need to be dumped to the total amount of broken rock. The greater the effective casting rate is, the lower the stripping cost of mine production is. Several typical sections are taken along the length of the blasting area, and the natural angle of repose of the loose materials inclined from the coal bench toe to the mined-out area is the effective casting plane (Figure 1). The effective casting volume is calculated by falling below the effective casting plane. The ratio of the material in the mined-out area to the total blasting rock volume is determined by

$$
\left\{\begin{array}{l}
\eta=\sum_{i=1}^{n} \frac{\eta_{i}}{n}, \\
\eta_{i}=\frac{S_{A}}{S_{A}+S_{B}+S_{C}+S_{D}},
\end{array}\right.
$$

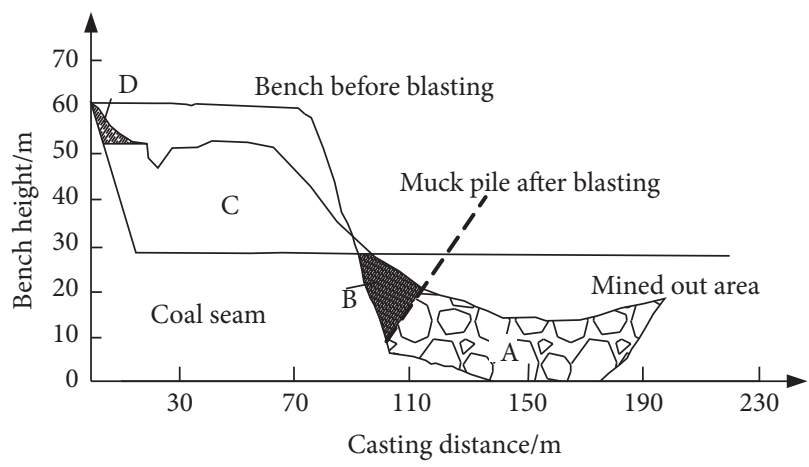

FIGURE 1: Schematic diagram of effective casting rate calculating model.

where $\eta$ is the effective casting rate; $\eta_{i}$ is the effective casting rate of the $i^{\text {th }}(i=1,2,3, \ldots, n)$ typical profile; $S_{A}, S_{B}, S_{C}$, and $S_{D}$ are the corresponding areas in the typical profile area, $\mathrm{m}^{2}$.

(4) Looseness coefficient: the looseness coefficient is the ratio of the loose volume after blasting to the original rock volume before blasting, which reflects the degree of rock fragmentation directly and also affects the settlement effect of the muck pile as well as the operating efficiency of the shoveling equipment [24]. It can be seen from Figure 1 that the looseness coefficient can be expressed as follows:

$$
k_{s}=\frac{S_{A}+S_{B}+S_{C}+S_{D}}{H \cdot W},
$$

where $k_{\mathrm{s}}$ is the blasting looseness coefficient; $W$ is the width of the blasting zone, $m$.

(5) Fragmentation distribution: fragmentation distribution can improve equipment operation efficiency and production organization management level. A high-definition camera is used to obtain the real image of the muck pile, and the fragmentation distribution of the muck pile is counted through the image recognition technology to evaluate the effect of fragmentation distribution.

(6) Muck pile shape: muck pile shape can reflect whether the blasting parameters and the charge structure are reasonable or not. At the same time, the pros and cons of muck pile shape of blast casting have a direct impact on the efficiency and cost of subsequent mining equipment. The evaluation of muck pile shape of blast casting is closely related to the equipment operation mode. Take the operation method which is dragline stand to extend platform as an example (Figure 2). Muck pile shape of blast casting directly affects the workload of auxiliary equipment and expanding the workload of platform, which in turn affects the efficiency of dragline operations.

(7) Boulder generation: the fragmentation of blasting affects the production efficiency of excavating equipment. Excessive fragmentation decreases the 


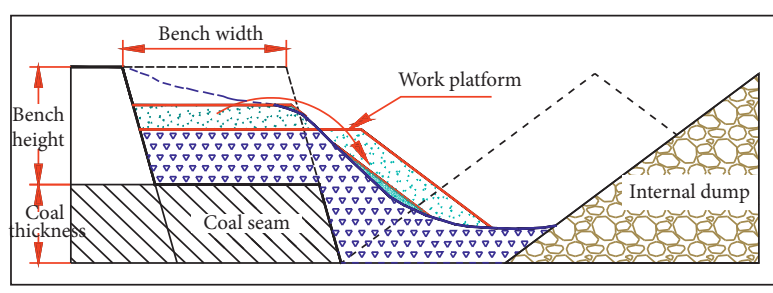

(a)

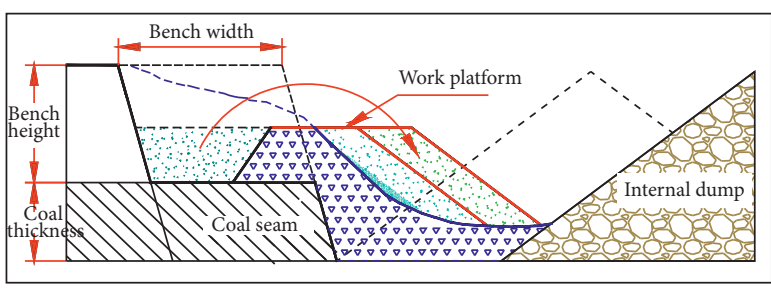

(b)

Figure 2: Section view of muck pile with dragline operation in extended platform. (a) Muck pile is leveled to establish an extended platform. (b) Dragline standing on the extended platform makes dumping operation.

efficiency of shoveling operations and increases the cost of secondary crushing; the smaller fragmentation is, the more explosive consumption and the higher blasting cost are. The relationship between boulder and the bucket volume is

$$
b \leq(0.75 \sim 0.80) \sqrt[3]{E},
$$

where $b$ is the longest side dimension of the block, $m$; $E$ is the bucket volume, $\mathrm{m}^{3}$.

(8) Destruction degree of coal seam bench: the ultradeep is an important measure for deep-hole bench blast casting to overcome the root. Due to the ultradepth of the blast hole, the explosive energy moves down to destroy the coal seam, causing the coal seam beneath the high bench to be mixed with stripped materials, which results in the lower quality of raw coal.

(9) Dust pollution: the high-bench blast casting has a large charge at a time, a large amount of blasting energy, and a large amount of blasting gas. Once detonated, a large amount of dense smoke and dust is formed, which will pollute the surrounding environment.

3.1.2. Establishment of Evaluation System. The selected evaluation indicators of blast casting results are represented by $v_{1}, v_{2}, v_{3}, v_{4}, v_{5}, v_{6}, v_{7}, v_{8}$, and $v_{9}$, respectively. Quantitative indicators are valued by actual measured values such as powder factor, limit vibration velocity, effective casting rate, and looseness coefficient; the grading standards of indicators are shown in Table 1. Qualitative indicators are valued by semiquantitative methods such as fragmentation distribution, muck pile shape, boulder generation, destruction degree of coal seam bench, and dust pollution; the grading and quantitative standards are shown in Table 2. Each evaluation indicator is divided into 4 levels (I $\sim$ IV), which are poor $\left(C_{1}\right)$, general $\left(C_{2}\right)$, well $\left(C_{3}\right)$, and very well $\left(C_{4}\right)$.

3.2. Membership Determination Based on Unascertained Measurement. A factor set composed of $n$ evaluation factors for a certain evaluation object is recorded as follows: $U=\left\{u_{1}\right.$, $\left.u_{2}, \ldots, u_{n}\right\}(i=1,2,3, \ldots, n)$, and each evaluation factor contains $m$ evaluation indicators. Indicators set is denoted as $V=\left\{v_{1}, v_{2}, \ldots, v_{m}\right\}(j=1,2,3, \ldots, m)$, where $x_{i j}$ represents the measured value of the $i^{\text {th }}$ evaluation factor $u_{i}$ related to the $j^{\text {th }}$ evaluation index $v_{j}$. There are $p$ evaluation levels for $x_{i j}$, and the evaluation set constituted is denoted as $T=\left\{C_{1}\right.$, $\left.C_{2}, \ldots, C_{p}\right\} . t_{i j k}=t\left(x_{i j} \in C_{k}\right)$ means that the measured value $x_{i j}$ belongs to the $k^{\text {th }}(k=1,2,3, \ldots, p)$ level. The single-index measurement value $t$ satisfies the following conditions [25]:

$$
\left\{\begin{array}{l}
0 \leq t\left(x_{i j} \in C_{k}\right) \leq 1, \\
t\left(x_{i j} \in C\right)=1, \\
t\left[x_{i j} \in \bigcup_{l=1}^{k} C_{l}\right]=\sum_{l=1}^{k} t\left(x_{i j} \in C_{l}\right) .
\end{array}\right.
$$

The linear measure function expression of the singleindex measure value $t$ is [26]

$$
\left\{\begin{array}{l}
t_{i}(x)= \begin{cases}\frac{-x}{a_{i+1}-a_{i}}+\frac{a_{i+1}}{a_{i+1}-a_{i}}, & a_{i}<x \leq a_{i+1}, \\
0, & x>a_{i+1}\end{cases} \\
t_{i+1}(x)= \begin{cases}0, & x \leq a_{i} \\
\frac{-x}{a_{i+1}-a_{i}}-\frac{a_{i+1}}{a_{i+1}-a_{i}}, & a_{i}<x \leq a_{i+1}\end{cases}
\end{array}\right.
$$

where $a_{i}$ is the observation value of the evaluation object in different levels $k ; x$ is the actual observation value of the evaluation object. Assuming that $x$ is on the left side of $a_{i}$, when the actual observation value increases from $a_{i}$ to $a_{i+1}$, the degree of membership of the corresponding level $k$ gradually decreases to 0 , and the degree of membership of the corresponding level $k+1$ gradually increases until it is 1 .

According to equation (5), the evaluation grade and value-determined standard of blast casting results are in Tables 1 and 2; the single-index measurement functions of evaluation indicators are determined, as shown in Figure 3.

3.3. Calculation of Indicator Weight. The Analytic Hierarchy Process is used to determine the subjective weight, the entropy method is used to determine the objective weight, and the Intuitionistic Fuzzy Set theory is used to determine the combined weight to ensure the rationality and accuracy of the evaluation result of blast casting results. 
TABLE 1: The grading standards of quantitative indicators for evaluating blast casting results.

\begin{tabular}{lccccc}
\hline Level & Blast casting result & Powder factor $/\left(\mathrm{kg} \cdot \mathrm{m}^{-3}\right)$ & Limit vibration velocity $/\left(\mathrm{cm} \cdot \mathrm{s}^{-1}\right)$ & Effective casting rate & Looseness coefficient \\
\hline I & Poor & $\geq 0.78$ & $\geq 2$ & $\leq 0.30$ & $\leq 1.15$ \\
II & General & $0.75 \sim 0.78$ & $1.5 \sim 2$ & $0.30 \sim 0.35$ & $1.15 \sim 1.20$ \\
III & Well & $0.72 \sim 0.75$ & $1 \sim 1.5$ & $0.35 \sim 0.4$ & $1.20 \sim 1.25$ \\
IV & Very well & $\leq 0.72$ & $\leq 1$ & $\geq 0.4$ & $\geq 1.25$ \\
\hline
\end{tabular}

TABLE 2: The grading and quantitative standards of qualitative indicators for evaluating blast casting results.

\begin{tabular}{|c|c|c|c|c|c|c|c|}
\hline Level & $\begin{array}{l}\text { Blast } \\
\text { casting } \\
\text { result }\end{array}$ & Assignment & $\begin{array}{c}\text { Fragmentation } \\
\text { distribution }\end{array}$ & Muck pile shape & Boulder generation & $\begin{array}{l}\text { Destruction } \\
\text { degree of coal } \\
\text { seam bench }\end{array}$ & Dust pollution \\
\hline I & Poor & 1 & $\begin{array}{l}\text { Fragmentation } \\
\text { distribution is } \\
\text { extremely } \\
\text { unreasonable }\end{array}$ & $\begin{array}{c}\text { Muck pile is loose } \\
\text { and shape is } \\
\text { unreasonable }\end{array}$ & $\begin{array}{l}\text { Too much boulder } \\
\text { is generated and } \\
\text { secondary } \\
\text { crushing should be } \\
\text { done }\end{array}$ & $\begin{array}{l}\text { Coal seam is } \\
\text { extremely } \\
\text { damaged }\end{array}$ & $\begin{array}{c}\text { Extremely high dust } \\
\text { concentration and } \\
\text { extremely serious } \\
\text { pollution }\end{array}$ \\
\hline II & General & 2 & $\begin{array}{c}\text { Fragmentation } \\
\text { distribution basically } \\
\text { meets the } \\
\text { requirements } \\
\end{array}$ & $\begin{array}{l}\text { Muck pile shape } \\
\text { basically meets the } \\
\text { requirements }\end{array}$ & $\begin{array}{l}\text { Too much boulder } \\
\text { is generated }\end{array}$ & $\begin{array}{l}\text { Coal seam is } \\
\text { seriously } \\
\text { damaged }\end{array}$ & $\begin{array}{l}\text { High dust } \\
\text { concentration and } \\
\text { serious pollution }\end{array}$ \\
\hline III & Well & 3 & $\begin{array}{l}\text { Fragmentation } \\
\text { distribution is } \\
\text { reasonable }\end{array}$ & $\begin{array}{l}\text { Muck pile is } \\
\text { relatively } \\
\text { concentrated }\end{array}$ & $\begin{array}{l}\text { Less boulder is } \\
\text { generated and } \\
\text { individual needs } \\
\text { crushing properly }\end{array}$ & $\begin{array}{l}\text { Coal seam is } \\
\text { basically well } \\
\text { preserved }\end{array}$ & $\begin{array}{c}\text { Low dust } \\
\text { concentration and } \\
\text { moderate pollution }\end{array}$ \\
\hline IV & Very well & 4 & $\begin{array}{l}\text { Fragmentation } \\
\text { distribution is fairly } \\
\text { uniform }\end{array}$ & $\begin{array}{l}\text { Muck pile is } \\
\text { concentrated, and } \\
\text { the shape } \\
\text { reasonable }\end{array}$ & $\begin{array}{l}\text { Boulder is not } \\
\text { generated }\end{array}$ & $\begin{array}{l}\text { Coal seam is } \\
\text { intact and } \\
\text { undamaged }\end{array}$ & $\begin{array}{l}\text { Lower dust } \\
\text { concentration and } \\
\text { light pollution }\end{array}$ \\
\hline
\end{tabular}

\subsubsection{Determination of Subjective Weight Based on Analytic} Hierarchy Process. Analytic Hierarchy Process determines the relative importance of various factors at different levels through pairwise comparison. The specific steps are as follows: (1) Construct a judgment matrix. The importances of all factor indicators are compared with each other, and a scale of 1-9 is used for assignment (Table 3). (2) Perform a hierarchical sorting and consistency test [27].

The weight of each indicator is calculated as follows [28]:

$$
W_{j}=\sqrt[p]{\prod_{k=1}^{p} t_{1 j k}} \quad(k=1,2, \ldots, p),
$$

where $t_{1 j k}$ is the measurement value of the $k^{\text {th }}$ level under the $j^{\text {th }}$ evaluation indicator of the single-index measurement; $W_{i}$ is the index weight.

After the weight of each indicator is determined, the maximum eigenvalue $\lambda_{\max }$ can be expressed as the following relationship [29]:

$$
\lambda_{\max }=\sum_{j=1}^{m} \frac{(A \cdot W)_{j}}{m \cdot D_{j}} \quad(j=1,2, \ldots, m),
$$

where $A$ is the judgment matrix; $\lambda_{\max }$ is the maximum eigenvalue.

Based on equation (11), the random consistency ratio of the judgment matrix $C R$ can be obtained by

$$
\left\{\begin{array}{l}
\mathrm{CI}=\frac{\lambda_{\max }-m}{m-1}, \\
\mathrm{CR}=\frac{\mathrm{CI}}{\mathrm{RI}},
\end{array}\right.
$$

where $C I$ is the consistency indicator; $R I$ is the average random consistency indicator; $C R$ is the random consistency ratio of the judgment matrix. When $C R<0.1$, the matrix meets the consistency requirement; otherwise, the matrix needs to be readjusted.

3.3.2. Determination of Objective Weight Based on Entropy Weight Method. According to the degree of variation of each evaluation indicator, the entropy weight method uses information entropy and deviation to calculate the weight of each indicator. The weight of each indicator can be determined by [30]

$$
\left\{\begin{array}{l}
D_{j}=1-\frac{1}{\ln p} \sum_{k=1}^{p} t_{1 j k} \ln t_{1 j k}, \\
W_{j}=\frac{D_{j}}{\sum_{j=1}^{m} D_{j}},
\end{array}\right.
$$




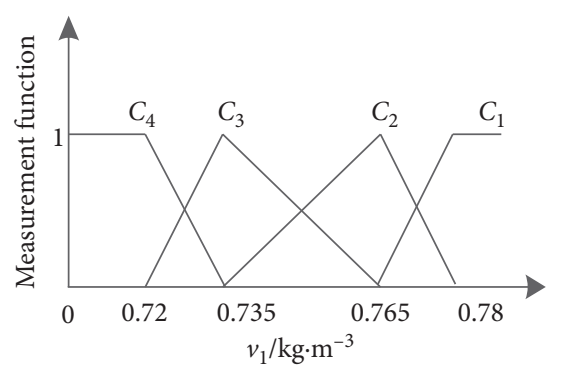

(a)

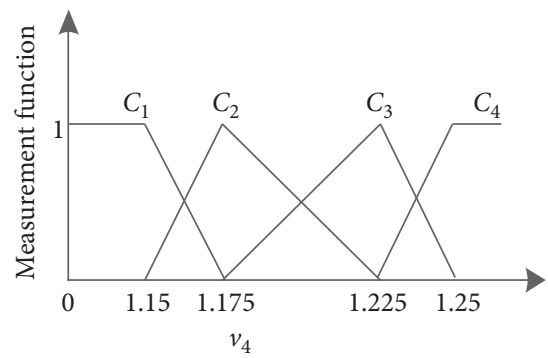

(d)

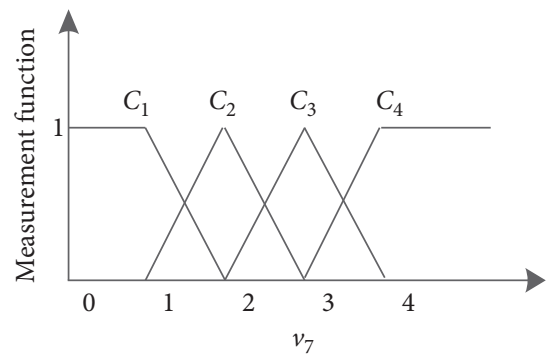

(g)

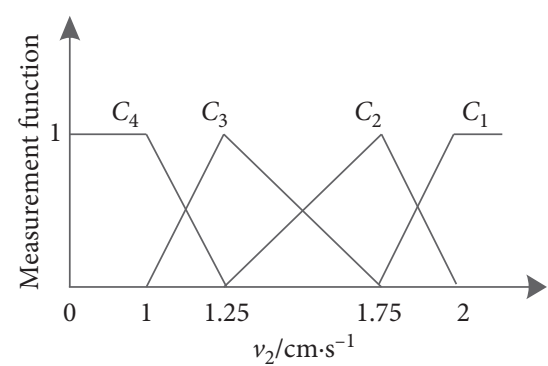

(b)

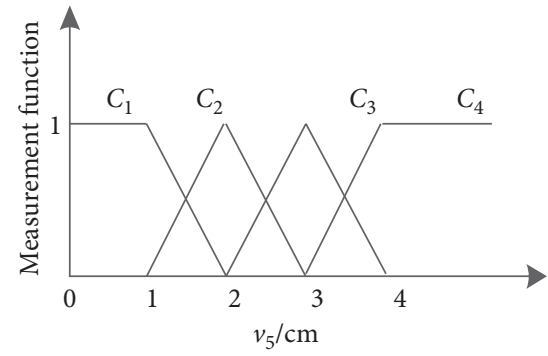

(e)

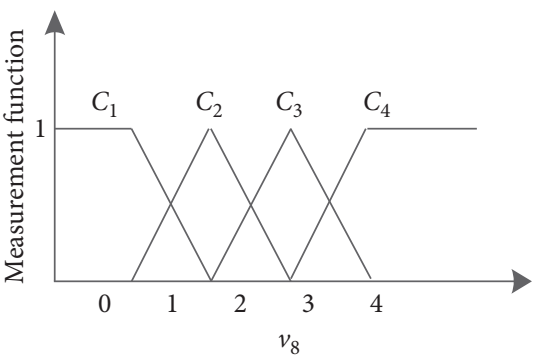

(h)

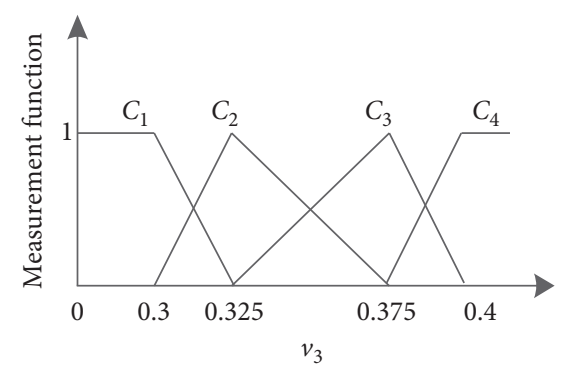

(c)

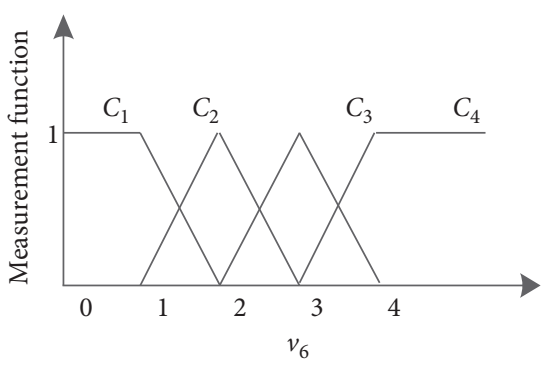

(f)

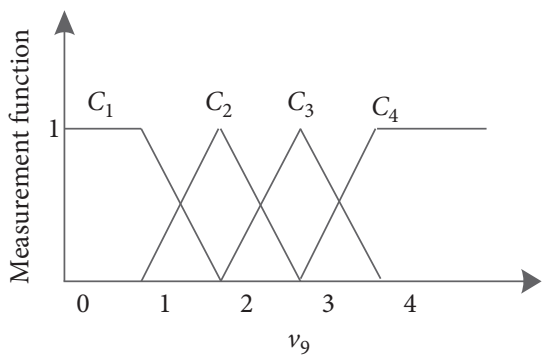

(i)

FIGURE 3: Unascertained measurement function of (a) powder factor; (b) limit vibration velocity; (c) effective casting rate; (d) looseness coefficient; (e) fragmentation distribution; (f) muck pile shape; (g) boulder generation; (h) destruction degree of coal seam bench; and (i) dust pollution.

TABLE 3: Meaning of important scale.

\begin{tabular}{lcc}
\hline Importance level & $a_{i j}$ & $a_{j i}$ \\
\hline$X_{\mathrm{i}}$ is as important as $X_{\mathrm{j}}$ & 1 & 1 \\
$X_{\mathrm{i}}$ is slightly more important than $X_{\mathrm{j}}$ & 3 & $1 / 3$ \\
$X_{\mathrm{i}}$ is obviously more important than & 5 & $1 / 5$ \\
$X_{\mathrm{j}}$ & 7 & $1 / 7$ \\
$X_{\mathrm{i}}$ and $X_{\mathrm{j}}$ are strongly important & 9 & $1 / 9$ \\
$X_{\mathrm{i}}$ and $X_{\mathrm{j}}$ are absolutely important & $2,4,6,8$ & $1 / 2,1 / 4,1 / 6,1 / 8$ \\
Interposed between & \multicolumn{2}{c}{}
\end{tabular}

where $t_{1 j k}$ is the measurement value of the $k^{\text {th }}$ level under the $j^{\text {th }}$ evaluation indicator of single-index measurement; $D_{j}$ is the degree of deviation; $W_{j}$ is the weight of each indicator.

3.3.3. Determination of Combined Weight Based on Intuitionistic Fuzzy Set. Assuming that the indicator weight interval is $[a, b]$, the transformed intuitionistic fuzzy weight interval is $\langle a, 1-b\rangle$, where $0 \leq a<b \leq 1, a$ is the importance degree of the weight, and $1-b$ is the nonimportance degree of the weight. The subjective weight of the evaluation indicator is as follows: $A=\left(A_{1}, A_{2}, A_{3}, A_{4}, A_{5}, A_{6}\right)$; and the objective weight is as follows: $B=\left(B_{1}, B_{2}, B_{3}, B_{4}, B_{5}, B_{6}\right)$. The combined weight expression is

$$
W_{n}=\left\langle\rho_{n}, \tau_{n}\right\rangle=<\min \left(A_{n}, B_{n}\right), 1-\max \left(A_{n}, B_{n}\right)>,
$$

where $W_{n}$ is the combined weight of the Intuitionistic Fuzzy Set; $\rho_{n}$ is the importance of the weight, respectively, and $\tau_{n}$ is the nonimportance of the weight; $0 \leq \rho_{n}+\tau_{n} \leq 1$.

3.4. Solving Framework of Evaluation Model. The main procedures of the evaluation model are described as follows:

(1) According to the single-index measurement function of the unascertained measurement, the measurement value $t_{i j k}$ of each indicator of the evaluation object is obtained, and a single-index measurement evaluation matrix is formed by all indicator measurement values as follows: 


$$
\left(t_{i j k}\right)_{n \times p}=\left[\begin{array}{cccc}
t_{i 11} & t_{i 12} & \cdots & t_{i 1 p} \\
t_{i 21} & t_{i 22} & \cdots & t_{i 2 p} \\
\vdots & \vdots & \vdots & \vdots \\
t_{i n 1} & t_{i n 2} & \cdots & t_{i n p}
\end{array}\right] .
$$

(2) The single-index measurement matrix is transformed into an intuitionistic fuzzy decision matrix. When the objective evaluation problems are dealt with by the standard interval $[a, b]$ type of intuitionistic fuzzy sets, the value of intuitionistic hesitation is usually 0.2 [31], which is used to improve the fuzziness expression ability of the evaluation model for qualitative indicators. The sample's intuitionistic fuzzy decision matrix $\boldsymbol{F}$ is

$$
F=\left[\begin{array}{cccc}
\left\langle\mu_{11}, v_{11}\right\rangle & \left\langle\mu_{11}, v_{12}\right\rangle & \cdots & \left\langle\mu_{1 p}, v_{1 p}\right\rangle \\
\left\langle\mu_{21}, v_{21}\right\rangle & \left\langle\mu_{22}, v_{22}\right\rangle & \cdots & \left\langle\mu_{2 p}, v_{2 p}\right\rangle \\
\vdots & \vdots & \vdots & \vdots \\
\left\langle\mu_{n 1}, v_{n 1}\right\rangle & \left\langle\mu_{n 2}, v_{n 2}\right\rangle & \cdots & \left\langle\mu_{n p}, v_{n p}\right\rangle
\end{array}\right] .
$$

(3) evaluation model, according to the intuitionistic fuzzy combination weight, the comprehensive value of the sample and the score value of each level are calculated, and the score value of each level is sorted. The corresponding level of the maximum score is the evaluation level of the sample's blast casting results. The comprehensive value $\bar{F}_{n p}$ and score value of each level $V_{p}$ are

$$
\begin{aligned}
\bar{F}_{n p} & =\left\langle\bar{\mu}_{n p}, \bar{v}_{n p}>=W_{n} F_{n p}\right. \\
& =\left\langle\rho_{n} \mu_{n p}, \tau_{n}+v_{n p}-\tau_{n} v_{n p}>,\right. \\
V_{p} & =\sum_{n=1}^{N} \bar{F}_{n p} .
\end{aligned}
$$

3.5. Analysis of Weight Ambiguity. The indicator weight affects the evaluation grade of blast casting results directly, and the intuitionistic fuzzy set is used to analyze the fuzziness of the evaluation indicator weight. Assuming that other conditions remain unchanged, the indicator weight $W_{n}=\left\langle\rho_{n}, \tau_{n}\right\rangle$ becomes $W_{n}=\left\langle\rho_{n}+\Delta \rho_{n}, \tau_{n}+\Delta \tau_{n}\right\rangle$, the evaluation result $C_{k-1}>C_{k}>C_{k+1}$ remains unchanged, and the intuitionistic fuzzy weight should satisfy the following condition:

$$
\left\{\begin{array}{l}
M_{n-1}>M_{n} \\
M_{n+1}>M_{n} \\
0 \leq \rho_{n}+\Delta \rho_{n}+\tau_{n}+\Delta \tau_{n} \leq 1 \\
0 \leq \rho_{n}+\Delta \rho_{n} \leq 1-\tau_{n} \\
0 \leq \tau_{n}+\Delta \tau_{n} \leq 1-\rho_{n}
\end{array}\right.
$$

where $\Delta \rho$ and $\Delta \tau$ are the change ranges of the importance degree and the nonimportance degree of the indicator weight, respectively.

According to the variation range of $\Delta \rho$ and $\Delta \tau$, the weight ambiguity $\zeta_{A n}$ of a certain indicator of sample $A$ is

$$
\zeta_{A n}=\frac{H_{A n}}{H_{n}},
$$

where $H_{A n}$ is the area determined by the inequality group (21) and $H_{n}$ is the area determined by the last three inequalities of the inequality group (21).

\section{Application Example}

4.1. Overview of the Research Area. Heidaigou Open-Pit Coal Mine is located in Zhunge'er Coalfield of Inner Mongolia Autonomous Region, with an approved production capacity of 34 million tons of raw coal per annum. The blast casting technique was used for the first time in 2007. After more than ten years of application and research, a complete system of blast casting-dragline stripping technology system has been formed. Besides, the effective casting rate of blast casting can reach $32 \%$, and more than 10 million $\mathrm{m}^{3}$ of rocks can be casted into the mined-out area every year, which can save 120 million RMB in annual production costs.

4.2. Data Processing. The measured data of the $\mathrm{N}^{\text {th }}$ blasting in 2019 is selected as sample, a total of $1574053 \mathrm{~m}^{3}$ of rock was blasted this time, $1149.06 t$ of explosives was consumed, and powder factor was $0.73 \mathrm{~kg} / \mathrm{m}^{3}$. The blasting vibration meter is used to monitor the intensity of blasting vibration in the blasting zone, and the peak limit vibration velocity is determined to be $1.38 \mathrm{~cm} / \mathrm{s}$. Data about the bench slope and mined-out area are scanned and integrated by the threedimensional laser scanner before and after the blasting; the three-dimensional digital photo of the muck pile shape of blast casting is visually obtained as shown in Figure 4(a). Section view was cut in the position of blast hole of threedimensional visualization diagram, and part of the section is shown in Figures $4(\mathrm{~b})-4(\mathrm{~d})$. The data information was counted on each section, and, according to equation (5), the effective casting rate and looseness coefficient of this blasting are calculated to be 0.352 and 1.27, respectively. According to the characteristic of muck pile shape which has concentrated shape and reasonable height as well as the grading and quantitative standards in Table 3, evaluation indicator of muck pile shape is quantified numerically.

In order to determine fragmentation distribution and boulder generation, the photos of muck pile shape taken at the scene were grayed and binarized, and the edges in the binary image were extracted using the canny operator to obtain the block distribution; part of the image processing is shown in Figure 5(a). The area of each edge was calculated and counted to obtain the frequency distribution of the block size as shown in Figure 5(b). According to the analysis and processing results of fragmentation distribution (Figure 5) as well as the grading and quantitative standards in 


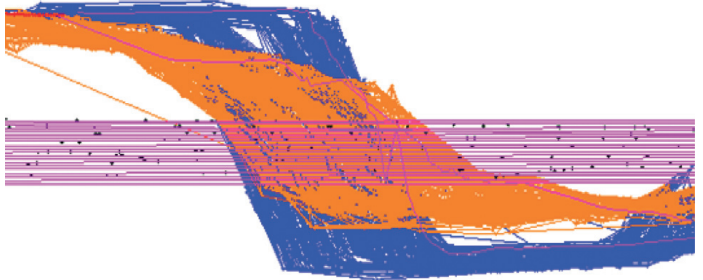

(a)

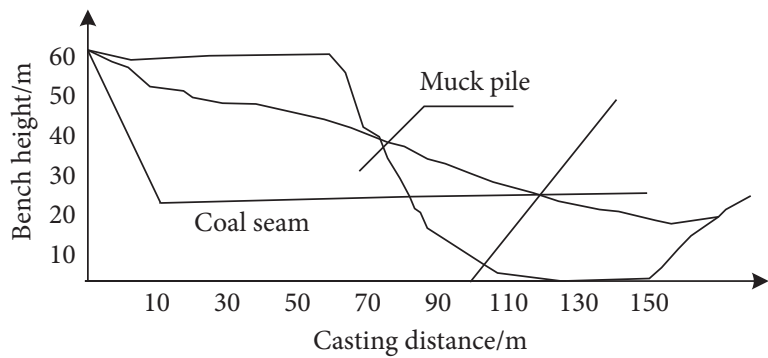

(c)

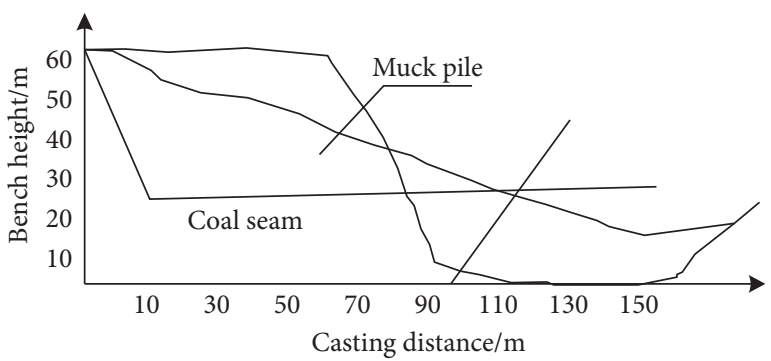

(b)

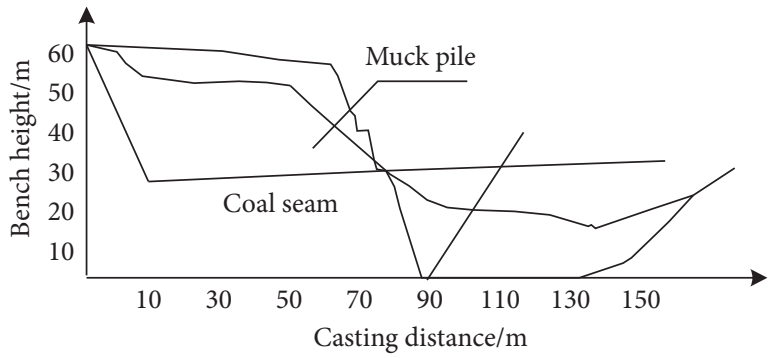

(d)

FIGURE 4: Schematic diagram of muck pile form of blast casting. (a) Scanned vector of muck pile shape. (b) N7- th $^{\text {th }}$ section view. (c) N7-13 ${ }^{\text {th }}$ section view. (d) N7-21 $1^{\text {th }}$ section view.

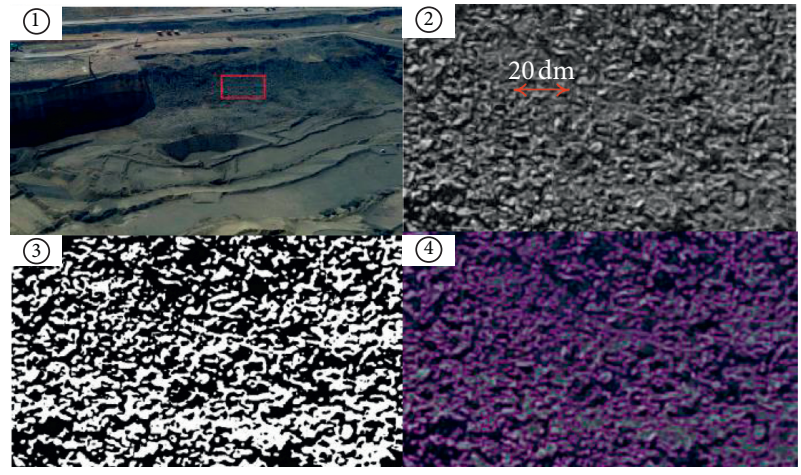

(a)

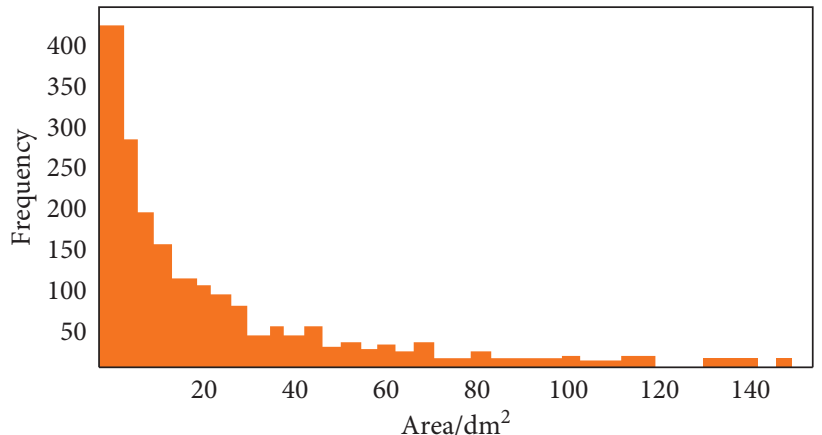

(b)

FIGURE 5: Analysis and processing results of fragmentation distribution. (a) Image processing. (b) Size statistics.

Table 3, evaluation indicators of fragmentation distribution and boulder generation are quantified numerically.

According to the muck pile shape of blast casting, the inflection point of the blasting surface is above the coal seam outcrop. Blast casting results did not wedge into the coal seam and cause the coal seam toss. The coal seam bench was intact (Figure 6). In addition, through the observation of the blasting site, Figure 7 shows that the thick yellowish-brown smoke produced during the blasting process is mainly caused by the explosive gas produced by the explosive reaction and a small amount of excessively crushed rock dust and dissipated gradually after spreading for a period of time; it reflects that the rock dust pollution caused by blast casting is moderate. Based on the above situation as well as the grading and quantitative standards in Table 3, evaluation indicators of destruction degree of coal seam bench and dust pollution are quantified numerically. Hence, the evaluation indicator values of all blast casting results are shown in Table 4.

\subsection{Data Calculation}

\subsubsection{Determination of Indicators Weight}

(1) Subjective weight. Analytic Hierarchy Process is used to solve the subjective weight of the evaluation indicators:

$A=\left(A_{1}, A_{2}, A_{3}, A_{4}, A_{5}, A_{6}, A_{7}, A_{8}, A_{9}\right)=(0.192,0.137$, $0.189,0.061,0.045,0.125,0.051,0.115,0.086)$. 


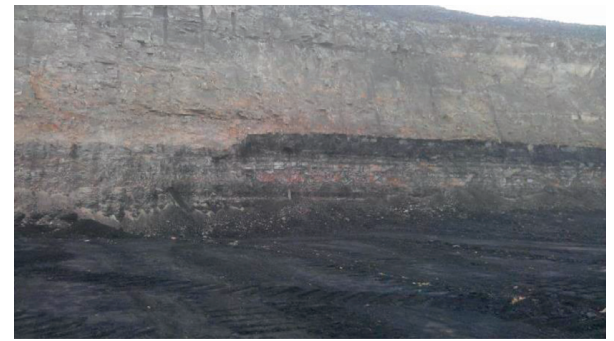

FIgURE 6: Destruction degree of coal seam bench.

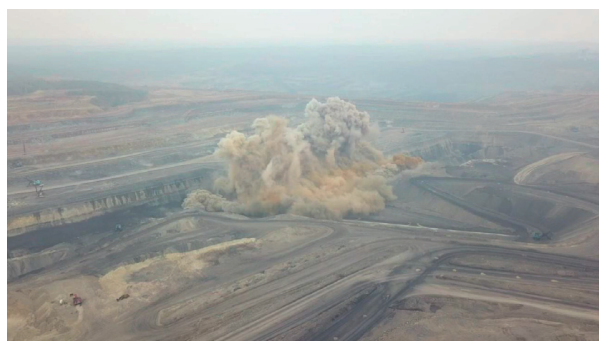

FIgURe 7: Dust pollution.

(2) Objective weight. The entropy weight method is used to determine objective weight of evaluation indicators:

$B=\left(B_{1}, B_{2}, B_{3}, B_{4}, B_{5}, B_{6}, B_{7}, B_{8}, B_{9}\right)=(0.071,0.077$, $0.066,0.131,0.131,0.131,0.131,0.131,0.131)$.

(3) Combination weight. The combination weight is obtained by equation (14):

$W=\left(\left\langle\rho_{1}, \tau_{1}\right\rangle,\left\langle\rho_{2}, \tau_{2}\right\rangle,\left\langle\rho_{3}, \tau_{3}\right\rangle,\left\langle\rho_{4}, \tau_{4}\right\rangle,\left\langle\rho_{5}, \tau_{5}\right\rangle\right.$, $\left\langle\rho_{6}, \tau_{6}\right\rangle,\left\langle\rho_{7}, \tau_{7}\right\rangle,\left\langle\rho_{8}, \tau_{8}>\right)=(<0.071,0.808>$, $<0.077,0.862>, \quad<0.066,0.811>,<0.061,0.869>$, $<0.045,0.869>,<0.125,0.869\rangle,<0.051,0.869>$, $<0.115,0.869\rangle,<0.086,0.869>)$.

4.3.2. Conversion of Evaluation Matrix. Each indicator value (Table 4) is substituted into measurement function of evaluation indicators in Figure 3, and the single-index evaluation matrix of the sample is obtained:

$$
\left(t_{1 j k}\right)_{9 \times 4}=\left[\begin{array}{cccc}
0 & 0 & 0.667 & 0.333 \\
0 & 0.26 & 0.74 & 0 \\
0 & 0.46 & 0.54 & 0 \\
0 & 0 & 0 & 1 \\
0 & 0 & 1 & 0 \\
0 & 0 & 0 & 1 \\
0 & 0 & 1 & 0 \\
0 & 0 & 0 & 1 \\
0 & 0 & 1 & 0
\end{array}\right] .
$$

Taking the definition of intuitionistic fuzzy set into account, the single-index evaluation matrix can be transformed into the single-index intuitionistic fuzzy set evaluation matrix as

$$
F_{9 \times 4}=\left[\begin{array}{cccc}
\langle 0,1\rangle & \langle 0,1\rangle & \langle 0.667,0.333\rangle & \langle 0.333,0.667\rangle \\
\langle 0,1\rangle & \langle 0.26,0.74\rangle & \langle 0.74,0.26\rangle & \langle 0,1\rangle \\
\langle 0,1\rangle & \langle 0.46,0.54\rangle & \langle 0.54,0.46\rangle & \langle 0,1\rangle \\
\langle 0,1\rangle & \langle 0,1\rangle & \langle 0,1\rangle & \langle 1,0\rangle \\
\langle 0,1\rangle & \langle 0,1\rangle & \langle 0.8,0\rangle & \langle 0,1\rangle \\
\langle 0,1\rangle & \langle 0,1\rangle & \langle 0,1\rangle & \langle 0.8,0\rangle \\
\langle 0,1\rangle & \langle 0,1\rangle & \langle 0.8,0\rangle & \langle 0,1\rangle \\
\langle 0,1\rangle & \langle 0,1\rangle & \langle 0,1\rangle & \langle 0.8,0\rangle \\
\langle 0,1\rangle & \langle 0,1\rangle & \langle 0.8,0\rangle & \langle 0,1\rangle
\end{array}\right] .
$$

Among them, since the quantitative indicators correspond to specific values, the hesitation degree is 0 ; meanwhile, for the qualitative indicator, the hesitation degree is 0.2 .

4.3.3. Determination of Evaluation Result. By multiplying the single-index intuitionistic fuzzy set evaluation matrix and the intuitionistic fuzzy combination weight based on equation (17), the weighted single-index intuitionistic fuzzy decision matrix $\overline{F_{9 \times 4}}$ can be obtained as follows: 
TABLE 4: Evaluation indicator of the blast casting results.

\begin{tabular}{lccc}
\hline Order & Subclass & Indicator & Value \\
\hline 1 & Economic benefit & Powder factor $\left(\mathrm{kg} / \mathrm{m}^{3}\right)$ & \\
2 & Environmental impact & Limit vibration velocity $(\mathrm{cm} / \mathrm{s})$ & 0.73 \\
3 & Blasting quality & Effective casting rate & 1.38 \\
4 & Blasting quality & Looseness coefficient & 0.352 \\
5 & Blasting quality & Fragmentation distribution & 1.27 \\
6 & Blasting quality & Muck pile shape & 3 \\
7 & Blasting quality & Boulder generation & 4 \\
8 & Blasting quality & Destruction degree of coal seam bench & 3 \\
9 & Environmental impact & Dust pollution & 4 \\
\hline
\end{tabular}

$$
\bar{F}_{9 \times 4}=\left[\begin{array}{cccc}
\langle 0,1\rangle & \langle 0,1\rangle & \langle 0.047,0.872\rangle & \langle 0.024,0.936\rangle \\
\langle 0,1\rangle & \langle 0.02,0.964\rangle & \langle 0.057,0.899\rangle & \langle 0,1\rangle \\
\langle 0,1\rangle & \langle 0.03,0.913\rangle & \langle 0.036,0.898\rangle & \langle 0,1\rangle \\
\langle 0,1\rangle & \langle 0,1\rangle & \langle 0,1\rangle & \langle 0.061,0.869\rangle \\
\langle 0,1\rangle & \langle 0,1\rangle & \langle 0.036,0.869\rangle & \langle 0,1\rangle \\
\langle 0,1\rangle & \langle 0,1\rangle & \langle 0,1\rangle & \langle 0.1,0.869\rangle \\
\langle 0,1\rangle & \langle 0,1\rangle & \langle 0.041,0.869\rangle & \langle 0,1\rangle \\
\langle 0,1\rangle & \langle 0,1\rangle & \langle 0,1\rangle & \langle 0.092,0.869\rangle \\
\langle 0,1\rangle & \langle 0,1\rangle & \langle 0.069,0.869\rangle & \langle 0,1\rangle
\end{array}\right] .
$$

Based on the single-index intuitionistic fuzzy decision matrix and equation (18), the comprehensive average value $V_{k}$ of the sample is calculated as follows:

$$
\left\{\begin{array}{l}
V_{1}=\sum_{n=1}^{4} \overline{F_{n 1}}=\langle 0,1\rangle \\
V_{2}=\sum_{n=1}^{4} \overline{F_{n 2}}=\langle 0.049,0.88\rangle \\
V_{3}=\sum_{n=1}^{4} \overline{F_{n 3}}=\langle 0.253,0.462\rangle \\
V_{4}=\sum_{n=1}^{4} \overline{F_{n 4}}=\langle 0.252,0.614\rangle
\end{array}\right.
$$

Therefore, the score value of the 4 levels about blast casting results is

$$
M=\left\{\begin{array}{l}
M_{1}\left(V_{1}\right) \\
M_{2}\left(V_{2}\right) \\
M_{3}\left(V_{3}\right) \\
M_{4}\left(V_{4}\right)
\end{array}\right\}=\left\{\begin{array}{c}
0.000-1.000 \\
0.049-0.88 \\
0.253-0.462 \\
0.252-0.614
\end{array}\right\}=\left\{\begin{array}{c}
-1.000 \\
-0.831 \\
-0.209 \\
-0.362
\end{array}\right\} .
$$

According to the magnitude relationship of the intuitionistic fuzzy numbers form $M_{1}\left(V_{1}\right)$ to $M_{4}\left(V_{4}\right)$, the order of the level of blast casting results is $C_{3}>C_{4}>C_{2}>C_{1}$. Therefore, the grade of blast casting results is level III, which means that the blast casting result is well.

At the same time, the evaluation model is compared with the fuzzy comprehensive evaluation method [15] and the cloud model evaluation method [16]. The processing capacity of the uncertainty information on the evaluation indicators is improved in evaluation model, and the single weighting method to determine the indicators weight is also avoided. The irrationality makes the evaluation result more reasonable and accurate and provides a new analysis idea and algorithm for the grading evaluation of blast casting result and the optimization of the indicators weight.

4.4. Fuzzy Analysis of Evaluation Indicator Weight. Changes in the weights of evaluation indicators will have a certain impact on the evaluation results. Taking the powder factor $v_{1}$ as an example, the ambiguity of this indicator is analyzed to explore the influence of the weight change of powder factor on the evaluation result. Under the premise that the comprehensive average value of the sample, the ranking result, and other conditions remain unchanged, the weight of the indicator powder factor $W_{1}=<\rho_{1}, \tau_{1} \geq<0.071$, $0.808>$ becomes $W_{1}{ }^{\prime}=\left\langle\rho_{1}+\Delta \rho_{1}, \tau_{1}+\Delta \tau_{1} \geq<0.071+\Delta \rho_{1}\right.$, $0.808+\Delta \tau_{1}>$, and the evaluation result is still $C_{3}>C_{4}>$ $C_{2}>C_{1}$; therefore, the weight range of powder factor is determined. On the basis of equation (19), the weight range of powder factor should be satisfied:

$$
\left\{\begin{array}{l}
M_{1}^{\prime}\left(V_{3}\right)>M_{1}^{\prime}\left(V_{4}\right), \\
M_{1}^{\prime}\left(V_{4}\right)>M_{1}^{\prime}\left(V_{2}\right), \\
M_{1}^{\prime}\left(V_{2}\right)>M_{1}^{\prime}\left(V_{1}\right), \\
0 \leq \rho_{1}+\Delta \rho_{1}+\tau_{1}+\Delta \tau_{1} \leq 1, \\
0 \leq \rho_{1}+\Delta \rho_{1} \leq 1-\tau_{1}, \\
0 \leq \tau_{1}+\Delta \tau_{1} \leq 1-\rho_{1} .
\end{array}\right.
$$

The value ranges of $\Delta \rho_{1}$ and $\Delta \tau_{1}$ in the inequality group are the change ranges of the importance degree and the nonimportance degree of weight of indicators powder factor. Furthermore, the weight ranges of other indicators can be obtained as shown in Table 5.

The shaded area shown in Figure 8 is the weight range of indicator determined by the inequality group. The smaller the proportion of the shaded area is, the smaller the fuzziness of the indicator weight is and the greater the sensitivity is. Combined with equation (20), the weight ambiguities of each indicator are calculated as $\zeta_{1}=0.708, \zeta_{2}=0.965$, $\zeta_{3}=0.181, \zeta_{4}=0.286, \zeta_{5}=1, \zeta_{6}=0.249, \zeta_{7}=1, \zeta_{8}=0.247$, and $\zeta_{9}=0.94$. The influence degree of each indicator weight 
TABLE 5: Fuzzy analysis of indicator weight.

\begin{tabular}{|c|c|c|}
\hline pt--Indicators & Variable ranges of $\Delta \rho$ and $\Delta \tau$ & Fuzziness \\
\hline Powder factor & $\left\{\begin{array}{l}0.256 \Delta \rho_{1}-0.136 \Delta \tau_{1}-0.092>0 \\
0.256 \Delta \rho_{1}-0.218 \Delta \tau_{1}+0.469>0 \\
-0.879 \leq \Delta \rho_{1}+\Delta \tau_{1} \leq 0.121 \\
-0.071 \leq \Delta \rho_{1} \leq 0.192 \\
-0.808 \leq \Delta \tau_{1} \leq 0.929\end{array}\right.$ & $\zeta_{1}=0.708$ \\
\hline Limit vibration velocity & $\left\{\begin{array}{l}0.585 \Delta \rho_{2}-0.38 \Delta \tau_{2}+0.027>0 \\
0.252 \Delta \rho_{2}-0.237 \Delta \tau_{2}-0.459<0 \\
-0.94 \leq \Delta \rho_{2}+\Delta \tau_{2} \leq 0.06 \\
-0.077 \leq \Delta \rho_{2} \leq 0.137 \\
-0.863 \leq \tau_{2} \leq 0.923\end{array}\right.$ & $\zeta_{2}=0.965$ \\
\hline Effective casting rate & $\left\{\begin{array}{l}0.418 \Delta \rho_{3}-0.278 \tau_{3}+0.153>0 \\
0.451 \Delta \rho_{3}-0.443 \Delta \tau_{3}-0.065<0 \\
-0.877 \leq \Delta \rho_{3}+\Delta \tau_{3} \leq 0.123 \\
-0.066 \leq \Delta \rho_{3} \leq 0.189 \\
-811 \leq \Delta \tau_{3} \leq 0.934\end{array}\right.$ & $\zeta_{3}=0.181$ \\
\hline Looseness coefficient & $\left\{\begin{array}{l}0.798 \Delta \rho_{4}-0.707 \Delta \tau_{4}-0.153<0 \\
0.798 \Delta \rho_{4}-0.707 \Delta \tau_{4}+0.469>0 \\
-0.93 \leq \Delta \rho_{4}+\Delta \tau_{4} \leq 0.07 \\
-0.061 \leq \Delta \rho_{4} \leq 0.131 \\
-0.869 \leq \Delta \tau_{4} \leq 0.939\end{array}\right.$ & $\zeta_{4}=0.286$ \\
\hline Fragmentation distribution & $\left\{\begin{array}{l}0.619 \Delta \rho_{5}-0.532 \Delta \tau_{5}+0.153>0 \\
-0.914 \leq \Delta \rho_{5}+\Delta \tau_{5} \leq 0.086 \\
-0.045 \leq \Delta \rho_{5} \leq 0.131 \\
-0.869 \leq \Delta \tau_{5} \leq 0.955\end{array}\right.$ & $\zeta_{5}=1$ \\
\hline Muck pile shape & $\left\{\begin{array}{l}0.665 \Delta \rho_{6}-0.706 \Delta \tau_{6}-0.153<0 \\
0.665 \Delta \rho_{6}-0.706 \Delta \tau_{6}+0.469>0 \\
-0.994 \leq \Delta \rho_{6}+\Delta \tau_{6} \leq 0.006 \\
-0.125 \leq \Delta \rho_{6} \leq 0.131 \\
-0.869 \leq \Delta \tau_{6} \leq 0.875\end{array}\right.$ & $\zeta_{6}=0.249$ \\
\hline Boulder generation & $\left\{\begin{array}{l}0.623 \Delta \rho_{7}-0.532 \Delta \tau_{7}+0.153>0 \\
-0.92 \leq \Delta \rho_{7}+\Delta \tau_{7} \leq 0.08 \\
-0.051 \leq \Delta \rho_{7} \leq 0.131 \\
-0.869 \leq \Delta \tau_{7} \leq 0.949\end{array}\right.$ & $\zeta_{7}=1$ \\
\hline Destruction degree of coal seam bench & $\left\{\begin{array}{l}0.659 \Delta \rho_{8}-0.706 \Delta \tau_{8}-0.153>0 \\
0.659 \Delta \rho_{8}-0.706 \Delta \tau_{8}+0.469<0 \\
-0.984 \leq \Delta \rho_{8}+\Delta \tau_{8} \leq 0.016 \\
-0.115 \leq \Delta \rho_{8} \leq 0.131 \\
-0.869 \leq \Delta \tau_{8} \leq 0.885\end{array}\right.$ & $\zeta_{8}=0.247$ \\
\hline Dust pollution & $\left\{\begin{array}{l}0.642 \Delta \rho_{9}-0.532 \Delta \tau_{9}+0.153>0 \\
-0.955 \leq \Delta \rho_{9}+\Delta \tau_{9} \leq 0.045 \\
-0.086 \leq \Delta \rho_{9}+0.131 \\
-0.869 \leq \Delta \tau_{9} 0.914\end{array}\right.$ & $\zeta_{9}=0.94$ \\
\hline
\end{tabular}

fuzziness on the evaluation result is different, and the effective casting rate ranks first in term of its influence, followed by damage degree of coal seam step, muck pile shape, looseness coefficient, powder factor, dust pollution, limit vibration velocity, and boulder generation/fragmentation distribution. Among them, the ambiguity of the effective casting rate is the smallest, indicating that change in indicator weight is the most sensitive to the evaluation results; meanwhile the fuzziness of the boulder generation and the distribution of lumps is 1, indicating that change in indicator weight has little impact on the evaluation results.

The above analysis shows that there is no correlation between the sensitivity of indicator weight and the numerical 


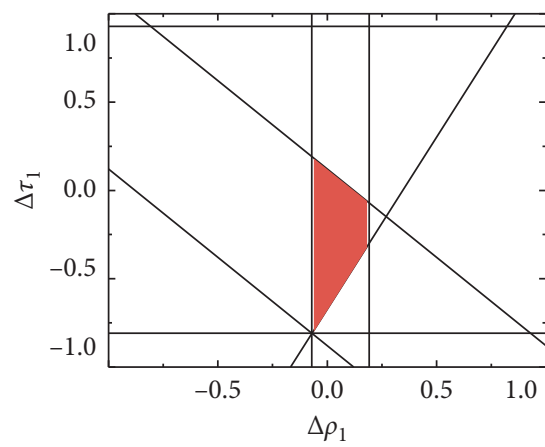

(a)

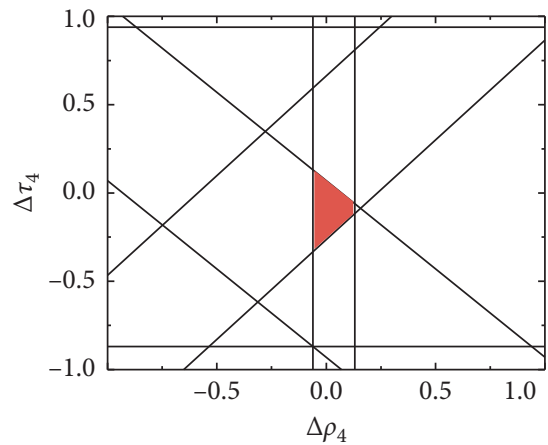

(d)

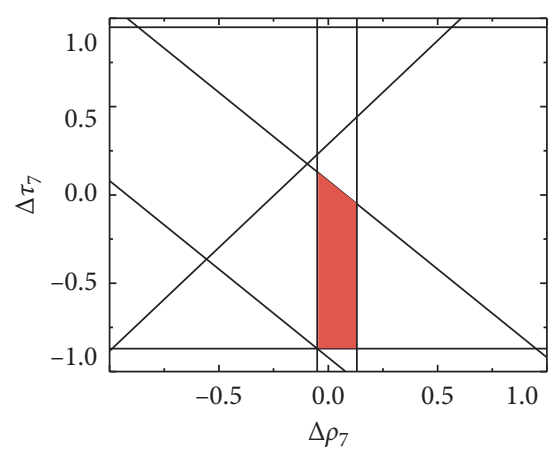

(g)

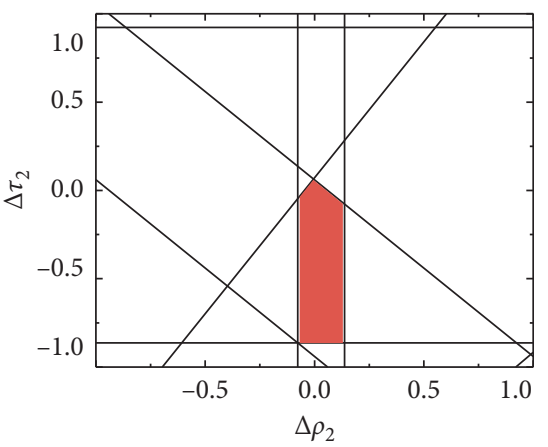

(b)

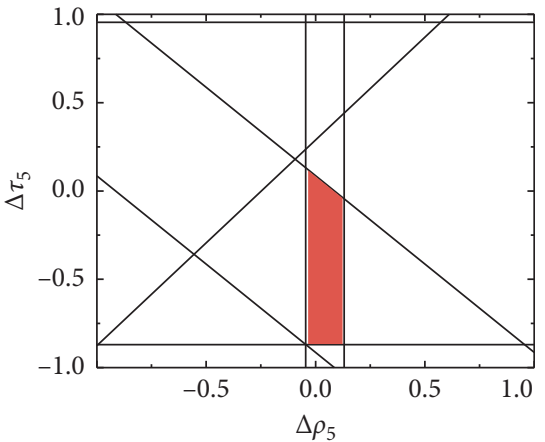

(e)

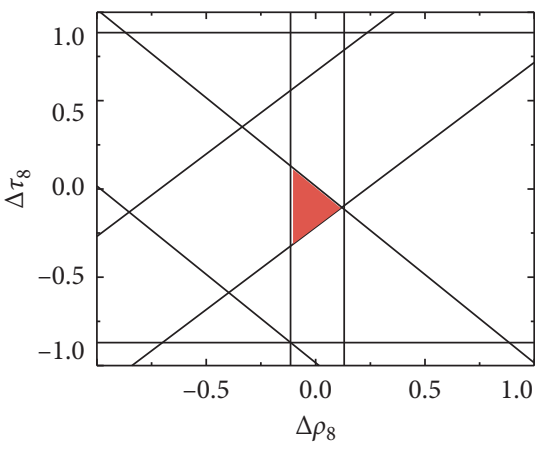

(h)

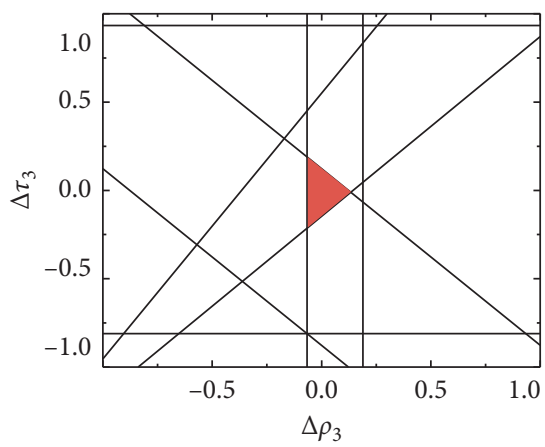

(c)

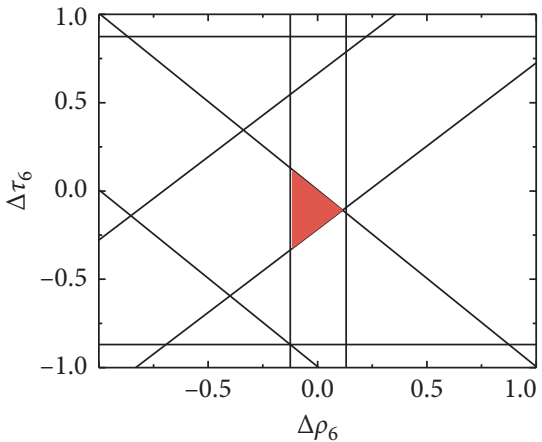

(f)

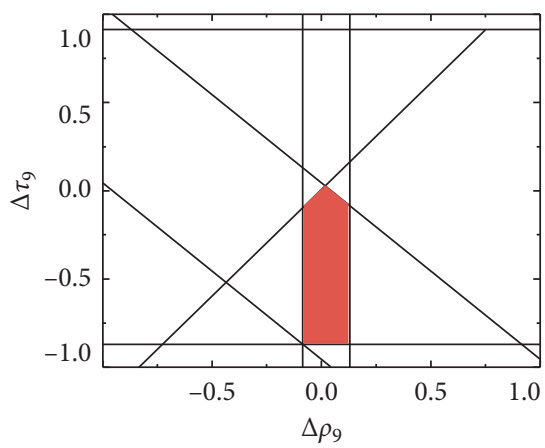

(i)

Figure 8: Fuzzy analysis of indicators weight: (a) powder factor, (b) limit vibration velocity, (c) effective casting rate, (d) looseness coefficient, (e) fragmentation distribution, (f) muck pile shape, (g) boulder generation, (e) destruction degree of coal seam bench, and (i) dust pollution.

value of the indicator weight. When evaluating blast casting results, the evaluation indicator with strong sensitivity should be carefully considered in many aspects when assigning indicator weights, and weighting methods should be used reasonably; the evaluation indicators with weak sensitivity can be simplified about the method steps when assigning the indicator weight. Thereby, the reliability of indicator weight can be improved, and an efficient and accurate evaluation model for blast casting results can be established. With the continuous accumulation of analysis samples, the fluctuating range of indicator weight can be gradually reduced and the reliability of indicator weights can be improved, which has theoretical significance for the importance analysis of indicators and the improvement of the accuracy of evaluation model.

\section{Conclusions}

(1) According to the characteristics of blast castingdragline stripping technology system, factors affecting blast casting results such as powder factor, limit vibration velocity, effective casting rate, looseness coefficient, fragmentation distribution, muck pile shape, boulder generation, destruction degree of coal seam bench, and dust pollution are comprehensively analyzed in terms of blasting quality, economic benefits, and environmental impact. These factors are used as the evaluation indicators of blast casting results and applied to the evaluation model based on unascertained measurement and intuitionistic fuzzy set. This provides 
important guidance for the selection of evaluation indicators of blast casting results in the future.

(2) The measured and processed data of blast casting in Heidaigou Open-Pit Coal Mine are calculated by model, the score value is -0.209 , and the evaluation level is III (well). The evaluation model improves the processing capacity of uncertain information about the evaluation indicators, avoids the irrationality of the single weighting method to determine the indictor weight, and makes the evaluation result more reasonable and accurate. It provides a new analysis idea and algorithm for the classification evaluation of blast casting results and the optimization of evaluation indicator weight.

(3) By calculating the fuzziness of the evaluation indicators of blast casting results, the weight ranges of evaluation indexes are given, and the influence degree of each indicator weight fuzziness on the evaluation result is different; the effective casting rate ranks first in terms of the influence, followed by damage degree of coal seam step, muck pile shape, looseness coefficient, powder factor, dust pollution, limit vibration velocity, and boulder generation/ fragmentation distribution. Meanwhile, the fuzzy analysis shows that there is no correlation between the sensitivity of indicator weight and the numerical value of the indicator weight. The analysis result has theoretical significance for the importance analysis of the indicators and improving the accuracy of evaluation model.

\section{Data Availability}

The data used to support the findings of this study are available from the corresponding author upon request.

\section{Conflicts of Interest}

The authors declare that there are no conflicts of interest regarding the publication of this paper.

\section{Acknowledgments}

This study was supported by the National Natural Science Foundation of China (51604264 and 52004202), Scientific Research Program Funded by Shaanxi Provincial Education Department (18JK0520 and 18JS067), Basic Natural Science Research Plan of Shaanxi Province (2019JQ-803), China Postdoctoral Science Foundation (2018M643691), and Shaanxi Innovation Capacity support program (2018TD038). Support from these agencies is gratefully acknowledged.

\section{References}

[1] P. D. Sharma, "Overburden side casting by blasting-an effective way of reducing operating cost in large opencast coal mines," Journal of Mines, Metals \& Fuels, vol. 52, no. 11, pp. 284-288, 2006.
[2] N. P. Chironis, “Angled drilling aids casting," Coal Age, vol. 89, no. 1, pp. 64-67, 1984.

[3] A. K. Mishra, M. Sinha, and M. Rout, "Cast blasting for improved mine economics," in Proceedings of the Blasting in Mining-New Trends:10th International Symposium on Rock Fragmentation by Blasting," FRAGBLAST, pp. 73-80, New York, NY, USA, November 2013.

[4] K. M. Li, Y. D. Zhang, and H. X. Fu, "Analysis of cast blasting paramenters in surface coal mines," Journal of Mining and Safety Engineering, vol. 23, no. 4, pp. 423-426, 2006.

[5] X. L. Li, "Effect of casting parameters on the cast percentage of high bench cast blasting," Transactions of Beijing Institute of Technology, vol. 31, no. 11, pp. 1265-1269, 2011.

[6] L. Ma, X. Lai, J. Zhang, S. Xiao, L. Zhang, and Y. Tu, "Blastcasting mechanism and parameter optimization of a benched deep-hole in an opencast coal mine," Shock and Vibration, vol. 2020, Article ID 1396483, 11 pages, 2020.

[7] Q. Yang, S. S. Xiao, and L. Ma, "Intelligent design method of casting blast parameters based on weighted clustering analysis," China Science Paper, vol. 19, no. 1, pp. 50-53, 2013.

[8] X. H. Ding, K. M. Li, W. M. Hu et al., "Prediction of optimum muck pile casting shape during blasting: a nonlinear theory," Journal of China University of Mining and Technology, vol. 41, no. 5, pp. 764-769, 2012.

[9] Y. H. Huang, S. L. Li, X. W. Fan et al., "Research and application of throwing blast effect prediction model of ELM neural network," Journal of China Coal Society, vol. 37, no. S1, pp. 65-69, 2012.

[10] L. Han, D. S. Liu, H. J. Li et al., "BP neural network forecast of blasting muck pile form of high bench cast blasting based on Weibull model," Journal of China Coal Society, vol. 38, no. 11, pp. 1947-1952, 2013.

[11] M. Monjezi, M. Rezaei, and A. Yazdian, "Prediction of backbreak in open-pit blasting using fuzzy set theory," Expert Systems with Applications, vol. 37, no. 3, pp. 2637-2643, 2010.

[12] X. H. Hu and X. S. Yang, "Comprehensive evaluation of blasting effect based on grey correlation analysis," Journal of Liaoning Technical University (Natural Science), vol. 27, no. S1, pp. 142-144, 2008.

[13] Z. Lei, S. R. Yang, and T. J. Tao, "Comprehensive evaluation of bench blasting effect based on uncertainty measurement theory," Journal of China Coal Society, vol. 40, no. 2, pp. 353-359, 2015.

[14] Q. K. Chen, W. L Zhao, Z. J. Guo et al., "Blasting effect evaluation model based on fuzzy neural network," Engineering Blasting, vol. 25, no. 4, pp. 74-79, 2019.

[15] L. Ma, K. M. Li, X. H. Ding et al., "Fuzzy synthetic evaluation on casting blast effect of Heidaigou surface coal mine," Metal Mine, vol. 40, no. 9, pp. 58-60, 2011.

[16] Z. L. Zhang, L. Ma, H. G. Peng et al., "Comprehensive evaluation of the casting blast effect in open-pit coal mine based on cloud model," Engineering Blasting, vol. 19, no. 1, pp. 40-43, 2013.

[17] H. Z. Zhao, Y. X. Wang, L. Li et al., "Evaluation of the casting blast effect based on integrated evaluation system," China Mining Magazine, vol. 29, no. 1, pp. 122-131, 2020.

[18] K. Atanassov, On Intuitionistic Fuzzy Sets Theory, SpringerVerlag, Berlin, Germany, 2012.

[19] E. Szmidt and J. Kacprzyk, "Using intuitionistic fuzzy sets in group decision making," Control and Cybernetics, vol. 31, no. 1, pp. 1037-1053, 2002.

[20] S.-P. Wan, G.-L. Xu, and J.-Y. Dong, "An Atanassov intuitionistic fuzzy programming method for group decision making with interval-valued Atanassov intuitionistic fuzzy 
preference relations," Applied Soft Computing, vol. 95, Article ID 106556, 2020.

[21] T. Beaubouef and F. E. Petry, "Uncertainty modeling for database design using intuitionistic and rough set theory," Journal of Intelligent \& Fuzzy Systems, vol. 20, no. 3, pp. 105-117, 2009.

[22] D. F. Li, Intuitionistic Fuzzy Set Decision and Game Analysis Methodologies, National Defense Industry Press, Beijing, China, 2012.

[23] M. Monjezi, M. Hasanipanah, and M. Khandelwal, "Evaluation and prediction of blast-induced ground vibration at Shur River Dam, Iran, by artificial neural network," Neural Computing and Applications, vol. 22, no. 7-8, pp. 1637-1643, 2013.

[24] S. S. Xiao, L. Ma, and X. H. Ding, "Optimization on bench parameters of casting blast based on multi-objective programming," Journal of Chain Coal Society, vol. 43, no. 9, pp. 2422-2431, 2018.

[25] G. Y. Wang, "Uncertainty information and its mathematical treatment," Journal of Harbin University of Civil Engineering and Architecture, vol. 23, no. 4, pp. 52-58, 1999.

[26] C. F. Huang, S. G. Tian, Q. Li et al., "Evaluation of rock quality of tunnel wall rock based on rough set theory and unascertained measurement theory," Mathematical Problems in Engineering, vol. 2018, Article ID 3471028, 10 pages, 2018.

[27] F. Ahmed and K. Kilic, "Fuzzy analytic hierarchy process: a performance analysis of various algorithms," Fuzzy Sets and Systems, vol. 362, pp. 110-128, 2019.

[28] S. P. Wan, F. Wang, and J. Y. Dong, "A group decision making method with interval valued fuzzy preference relation based on the geometric consistency," Information Fusion, vol. 40, pp. 87-100, 2017.

[29] O. S. Vaidya and S. Kumar, "Analytic hierarchy process: an overview of applications," European Journal of Operational Research, vol. 169, no. 1, pp. 1-29, 2006.

[30] Y. Lu, Y. C. Ye, X. Y. Lu et al., "Optimal selection of mining method by attribute interval recognition model based on empowerment combination theory," Metal Mine, vol. 46, no. 7, pp. 25-30, 2017.

[31] M. W. Wang and J. L. Jing, Relation Number Theory and Application, Science press, Beijing, China, 2017. 